\title{
Relationship between workload and nurse performance at the Rawamangun Special Surgery Hospital in 2021
}

\section{Author : \\ Siti Juhairiyah', Deasy \\ Febriyanty2, Mayumi \\ Nitami ${ }^{3}$, Erlina \\ Puspitaloka ${ }^{4}$}

First Author E-mail: riajuhaisiti@student.esaunggul .ac.id, Universitas Esa Unggul, Indonesia.

deasy.febriyanty@esaunggul.a c.id, Universitas Esa Unggul, Indonesia.

DOI :10.24903/kujkm.v7i2.1168

Received : November 2021

Accepted : November 2021

Published : Desember 2021

P-ISSN: 2477-1880 E-ISSN: 2502-6623 Kesmas Uwigama : Jurnal Kesehatan Masyarakat

\begin{abstract}
Background: Nurse performance is a measure of success in achieving nursing service goals. Good and bad performance is also influenced by workload, high workload will adversely affect the performance of nurses, poor performance of nurses will affect careers, rewards, no promotion system, and no punishment for poor performance. Based on data from the Ministry of Health of the Republic of Indonesia in 2015, the highest number of health workers was nurses as many as 147,264 people (45.65\%). In Indonesia, professional nurses only make up $2 \%$ of the total existing nurses. This figure is much lower than the Philippines, which has reached $40 \%$ with one and two strata education
\end{abstract}

Objectives: This study aims to determine the relationship between workload and nurse performance at the Rawamangun Special Surgery Hospital in 2021.

Research Metodes: This study uses a Cross Sectional design. The sampling method used was Total Sampling with a total sample of 30 respondents. Data analysis in this study is univariate analysis and bivariate analysis with Chi Square test.

Findings: The results of the univariate analysis showed the highest proportion of good performance was $53.3 \%$, and the highest proportion of light workloads was $63.3 \%$. The results of the bivariate analysis showed that $P R=0.96 ; 95 \% \mathrm{Cl}=0.430-2.141$. Conclusion: There is no relationship between workload and nurse performance at the Rawamangun Special Surgery Hospital in 2021.

Keywords: Performance, Workload.

\section{Abstrak}

Latar Belakang: Kinerja perawat merupakan ukuran keberhasilan dalam mencapai tujuan pelayanan keperawatan. Kinerja yang baik dan buruk juga dipengaruhi oleh beban kerja, tingginya beban kerja akan berdampak buruk bagi kinerja perawat, buruknya kinerja dari perawat akan mempengaruhi karir, reward, tidak adanya sistem promosi, dan tidak adanya punishment terhadap kinerja yang buruk. Berdasarkan data kemenkes RI tahun 2015 jumlah tenaga kesehatan terbanyak yaitu perawat sebanyak 147.264 orang $(45,65 \%)$. Di Indonesia, perawat profesional baru mencapai $2 \%$ dari total perawat yang ada. Angka ini jauh lebih rendah dibandingkan dengan Filipina yang sudah mencapai $40 \%$ dengan pendidikan strata satu dan dua.

Tujuan: Untuk mengetahui hubungan beban kerja dengan kinerja perawat di RS Khusus Bedah Rawamangun Tahun 2021.

Metode Penelitian: Adapun dalam penelitian ini menggunakan desain Cross Sectional. Metode dalam pengambilan sampel menggunakan Total Sampling dengan jumlah sampel sebanyak 30 responden. Data analisis pada penelitian ini yaitu analisis univariat dan analisis bivariat dengan Uji Chi Square.

Temuan: Hasil dari analisis univariat menunjukkan proporsi tertinggi kinerja baik sebesar 53,3\%, dan proporsi tertinggi beban kerja ringan sebesar 63,3\%. Hasil analisis bivariat menunjukkan bahwa $\mathrm{PR}=0.96 ; 95 \% \mathrm{Cl}=0.430-2.141$.

Kesimpulan: Tidak ada hubungan antara beban kerja dengan kinerja perawat di RS Khusus Bedah Rawamangun Tahun 2021.

Kata kunci: Kinerja, Beban Kerja.

\section{Copyright Notice

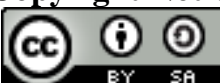

This work is licensed under Creative Commons Attribution 4.0 International License. 


\section{Pendahuluan}

Perawat adalah tenaga profesional yang perannya tidak dapat dikesampingkan dari baris terdepan pelayanan rumah sakit (Nursalam, 2014). Adapun profesi perawat sebagai pemberi pelayanan jasa berada digaris terdepan dan merupakan komponen yang sangat menentukan baik buruknya citra rumah sakit. Kinerja (performance) adalah tingkat prestasi atau hasil nyata seseorang yang dihitung secara periodik baik kualitas maupun kuantitas berdasarkan sasaran, standar dan kriteria yang telah ditetapkan sebelumnya sebagai hasil kewenangan dan tanggung jawab sebuah pekerjaan dalam suatu perusahaan atau organisasi (Sinaga et al., 2020). Kinerja perawat merupakan ukuran keberhasilan dalam mencapai tujuan pelayanan keperawatan. Kinerja perawat dalam pemberian asuhan keperawatan adalah kemampuan atau pembelajaran yang diterima selama menyelesaikan program Pendidikan keperawatan (Ali, 2002). Sedangkan menurut Sunnia (2018) kinerja perawat adalah hasil dari penilaian kerja perawat dalam melaksanakan tugas dan tanggung jawab sebagai seorang perawat dalam melakukan asuhan keperawatan yang terdiri dari lima tahap yaitu tahap pengkajian, diagnosa keperawatan, perencanaan, implementasi dan evaluasi.

Berdasarkan Permenkes RI nomor 10 tahun 2015 tentang Standar Pelayanan Keperawatan di Rumah Sakit Khusus, penilaian kinerja menjadi salah sau indikator pada penugasan kerja perawat dan untuk penempatan perawat. Kinerja perawat yang kurang baik juga akan berdampak pada produktivitas rumah sakit, sehingga organisasi perlu memberi perhatian kepada berbagai macam kebutuhan pegawainya untuk meningkatkan kinerja pegawainya (Aprilia et al., 2017). Kinerja yang baik dan buruk juga dipengaruhi oleh beban kerja, tingginya beban kerja akan berdampak buruk bagi kinerja perawat, buruknya kinerja dari perawat akan mempengaruhi karir, reward, tidak adanya sistem promosi, dan tidak adanya punishment terhadap kinerja yang buruk (Kurniati \& Efendi, 2012). Berdasarkan data kemenkes RI tahun 2015 jumlah tenaga kesehatan terbanyak yaitu perawat sebanyak 147.264 orang (45,65\%). Di Indonesia, perawat profesional baru mencapai $2 \%$ dari total perawat yang ada. Angka ini jauh lebih rendah dibandingkan dengan Filipina yang sudah mencapai $40 \%$ dengan pendidikan strata satu dan dua (Sri, 2009).

Beban kerja perawat adalah volume kerja perawat disetiap rumah sakit, adapun beban kerja sangat penting untuk mengetahui keseimbangan antara tenanga perawat dengan beban kerja (Vanchapo, 2020). Kurangnya tenaga perawat di dalam rumah sakit akan membuat perawat jadi memiliki beban kerja yang berat dikarenakan harus dua kali lebih besar beban kerja yang di dapat dari sebelumnya. Ketika perawat memiliki beban kerja yang ringan seperti kurangnya pasien maka perawat dapat melakukan pekerjaan dengan maksimal, akan tetapi sebaliknya jika perawat memiliki beban kerja yang berat maka kinerja perawat akan menjadi kurang maksimal (Tulasi et al., 2021). 
Berdasarkan hasil studi pendahuluan, melalui wawancara kepada kepala unit IGD, kepala unit OK(Operasi), kepala unit rawat jalan, dan kepala unit rawat inap diperoleh hasil bahwa kinerjanya kurang optimal karena ada beberapa tugas tidak dikerjakan. Serta didukung dari hasil data HRD pada tahun 2020 menyatakan bahwa kinerja dari 34 perawat terdapat 7 perawat yang masing-masing memiliki nilai sebesar $55 \%$.

Berdasarkan uraian diatas maka peneliti ingin melihat hubungan beban kerja dengan kinerja, berdasarkan permasalahan kinerja pada perawat. Oleh karena itu peneliti akan melakukan penelitian mengenai "Hubungan Beban Kerja dengan Kinerja Perawat di Rumah Sakit Khusus Bedah Rawamangun Pada Tahun 2021".

\section{Metode Penelitian}

Adapun jenis penelitian yang digunakan dalam penelitian ini yaitu penelitian kuantitatif dengan desain cross sectional. Data yang digunakan adalah data primer dan data sekunder, data primer diperoleh dari hasil wawancara dan hasil dari kuesioner tiap variabel yang diteliti, sedangkan untuk data sekunder diperoleh dari data HRD dan Rekam Medis RS Khusus Bedah Rawamangun. Dalam pengambilan sampel menggunakan Teknik Total Sampling, yang dimana jumlah sampel yang digunakan adalah 30 responden. Pada Uji Validitas dan Uji Reliabilitas telah dilakukan. Lalu dilakukannya Uji Normalitas dengan menggunakan Uji Shapiro-Wilk, dimana digunakan untuk pengambilan keputusan. Nilai signifikan pada Uji Shapiro-Wilk pada beban kerja dan kinerja yaitu $<0,05$ yang artinya nilai cut of point menggunakan nilai median.

\section{Hasil Penelitian}

\section{Univariat}

Analisis univariat dilakukan bertujuan untuk menghasilkan distribusi frekuensi dari variabel dependen (kinerja) dan variabel independen (beban kerja). Dimana penelitian ini dilakukan kepada 30 perawat di RS Khusus Bedah Rawamangun Tahun 2021. Adapun hasil analisis univariat sebagai berikut:

\begin{tabular}{|l|c|c|c|}
\hline \multicolumn{2}{|c|}{ Variabel } & $\begin{array}{c}\text { Frekuensi } \\
(\mathbf{N})\end{array}$ & $\begin{array}{c}\text { Persentase } \\
(\%)\end{array}$ \\
\hline \multicolumn{2}{|l|}{ Dependen } \\
\hline \multirow{2}{*}{ Kinerja } & Kurang & 14 & $46,7 \%$ \\
\cline { 2 - 4 } & Baik & 16 & $53,3 \%$ \\
\hline \multicolumn{3}{|l}{ Independen } \\
\hline $\begin{array}{l}\text { Beban } \\
\text { Kerja }\end{array}$ & Berat & 11 & $36,7 \%$ \\
\cline { 2 - 4 } & Ringan & 19 & $63,3 \%$ \\
\hline
\end{tabular}

Tabel 1. Hubungan Beban Kerja Dengan Kinerja Perawat di RS Khusus Bedah Rawamangun Tahun 2021

Berdasarkan tabel 1 , menunjukkan bahwa kinerja perawat baik sebanyak 53,3\% dan beban kerja perawat ringan sebanyak $63,3 \%$.

\section{Bivariat}

Hubungan Beban Kerja Dengan Kinerja Perawat di RS Khusus Bedah Rawamangun Tahun 2021.

\begin{tabular}{|c|c|c|c|c|c|}
\hline \multirow{3}{*}{$\begin{array}{l}\text { Beban } \\
\text { Kerja }\end{array}$} & \multicolumn{4}{|c|}{ Kinerja } & \multirow{3}{*}{$\begin{array}{l}P \text { - } \\
\text { Value }\end{array}$} \\
\hline & \multicolumn{2}{|c|}{$\begin{array}{c}\text { Kurang } \\
\text { Baik }\end{array}$} & \multicolumn{2}{|c|}{ Baik } & \\
\hline & $\mathbf{N}$ & $\%$ & $\mathbf{N}$ & $\%$ & \\
\hline Berat & 5 & $45,5 \%$ & 6 & $54,5 \%$ & 1.000 \\
\hline
\end{tabular}




\begin{tabular}{|l|l|l|l|l|l|}
\hline Ringan & 9 & $47,7 \%$ & 10 & $52,6 \%$ & \\
\hline
\end{tabular}

Tabel 2. Hubungan Beban Kerja Dengan Kinerja Perawat di RS Khusus Bedah Rawamangun Tahun 2021

Berdasarkan tabel 2, didapatkan hasil dari 30 responden didapatkan hasil analisis dengan proporsi tertinggi yaitu kinerja baik dengan beban kerja ringan sebanyak 10 perawat (52.6\%), sedangkan kinerja baik dengan beban kerja berat sebanyak 6 perawat (54.5\%). Dilihat dari hasil $p$-value $=1.000$ dengan nilai $\alpha=0,05$ yang berarti dapat disimpulkan bahwa tidak ada hubungan antara beban kerja dengan kinerja pada perawat di RS Khusus Bedah Rawamangun Tahun 2021.

\section{Pembahasan}

\section{Hubungan Beban Kerja Dengan Kinerja Perawat di RS Khusus Bedah Rawamangun Tahun 2021}

Terjadinya tidak ada hubungan antara beban kerja dan kinerja perawat secara langsung terlepas dari masing-masing individu perawat yang dimana dari 30 perawat didalam penelitian ini memiliki unit kerja berbeda yang terbagi pada 4 unit yaitu unit rawat inap, unit rawat jalan, unit IGD dan unit OK (Operasi). Dimana disetiap unit memiliki beban kerja yang berbeda-beda yang dapat mempengaruhi kinerja perawat itu sendiri. Hal tersebut disebabkan oleh suatu hal seperti iklim organisasi dan lingkungan kerja. Tidak terdapat hubungan juga bisa disebabkan karena pada penelitian ini dilakukan penilaian secara subjektif, dimana penilaian subjektif itu melakukan penilaian oleh diri sendiri seperti persepsi dari masing-masing individu, dan juga bisa disebabkan oleh sedikitnya jumlah responden dalam penelitian ini yang membuat tidak ada hubungan antara beban kerja dengan kinerja perawat.

Adapun pada penelitian ini beban kerja tidak berhubungan dengan kinerja, kemungkinan dari hasil observasi didapatkan faktor yang mempengaruhi kinerja yaitu iklim organisasi dan lingkungan kerja. Hal ini sesuai dengan teori yang dikemukakan oleh Widan \& Sa'adah (2021) yang menyatakan bahwa Faktor yang mempengaruhi kinerja yaitu pada faktor internal terdapat kemampuan, motivasi, kepribadian dan beban kerja sedangkan dari faktor eksternal terdapat kepemimpinan, iklim organisasi dan lingkungan kerja.

\section{Kesimpulan}

1. Tidak terdapat adanya hubungan antara beban kerja dengan kinerja perawat di RS Khusus Bedah Rawamangun Tahun 2021, dimna didapatkan hasil P-Value $1.000>0,05$.

2. Didapatkan hasil bahwa perawat di RS Khusus Bedah Rawamangun Tahun 2021 memiliki kinerja yang baik sebanyak 63,3\%.

3. Didapatkan hasil bahwa perawat di RS Khusus Bedah Rawamangun Tahun 2021 memiliki beban kerja yang ringan sebanyak 52,6\%.

\section{Referensi}

Ali, Z. (2002). Dasar-Dasar Keperawatan Profesional. EGC.

Aprilia, F., Samsir, S., \& Pramadewi, A. (2017). Pengaruh Beban Kerja, Stres Kerja Dan Motivasi Kerja Terhadap Kinerja Perawat Rumah Sakit Islam 
Ibnu Sina Pekanbaru. Jurnal Online

Mahasiswa Fakultas Ekonomi

Universitas Riau, 4(1), 87-100.

Kurniati, A., \& Efendi, F. (2012). Kajian

Sumber Daya Manusia Kesehatan di Indonesia. In Salemba Medika (Issue January 2012).

https://doi.org/10.13140/RG.2.1.144 0.6804

Nursalam. (2014). Manajemen Keperawatan Aplikasi dalam Praktik Keperawatan Profesional (P. P. Lestari (ed.); 4th ed.). Salemba Medika.

Sinaga, O. sari, Hasibuan, A., Efendi, E., Priyojadmiko, E., Butarbutar, M., Purba, S., Karwanto, K., Silalahi, M., Hidayatullah, A. nurrochman, \& Mauliana, M. (2020). Manajemen Kinerja Dalam Organisasi (J. Simarmata (ed.)). Yayasan Kita Menulis.

Sri. (2009). Faktor-Faktor Yang Berhubungan Dengan Kinerja Perawat Pada Puskesmas Perawatan di Kabupaten Konawe Tahun 2009.

Sunnia, A. (2018). Kinerja Perawat Rumah Sakit Lavalette Malang. 10(1), 1-9. https://doi.org/10.1103/PhysRevB.10 1.089902\%0Ahttp://dx.doi.org/10.10 16/j.nantod.2015.04.009\%0Ahttp://d x.doi.org/10.1038/s41467-018055149\%0Ahttp://dx.doi.org/10.1038/s414 67-019-13856-

1\%0Ahttp://dx.doi.org/10.1038/s414 67-020-14365-

2\%0Ahttp://dx.doi.org/1

Tulasi, M., Sinaga, M., \& Kenjam, Y. (2021). Faktor Yang Berhubungan Dengan Kinerja Perawat Di Rumah Sakit Umum Daerah Kefamenanu Kabupaten Timor Tengah Utara. Media Kesehatan Masyarakat Indonesia, 16(1), 15-25. https://journal.unhas.ac.id/index.php /mkmi/article/view/487

Vanchapo, A. R. (2020). BEBAN KERJA dan STRES KERJA. Qiara Media.

Widan, M. A., \& Sa'adah, L. (2021). Pentingnya Motivasi Untuk Meningkatkan Kinerja Karyawan. Lembaga Penelitian dan Pengabdian Kepada Masyarakat Universitas KH.A.Wahab Hasbullah. 